\title{
Intermittent Small Baseline Subset (ISBAS) monitoring of land covers unfavourable for conventional C-band InSAR: proof-of-concept for peatland environments in north Wales, UK
}

\author{
${\text { Francesca Cigna }{ }^{* a} \text {, Andrew Sowter }}^{\mathrm{b}}$, Colm J. Jordan ${ }^{\mathrm{a}}$, Barry G. Rawlins ${ }^{\mathrm{a}}$ \\ ${ }^{a}$ British Geological Survey, Natural Environment Research Council, Keyworth, United Kingdom; \\ ${ }^{\mathrm{b}}$ Nottingham Geospatial Institute, University of Nottingham, Nottingham, United Kingdom
}

\begin{abstract}
This paper provides a proof-of-concept for the use of the new Intermittent Small Baseline Subset (ISBAS) approach to study ground elevation changes in areas of peat and organic soils in north Wales, which are generally, unfavourable for conventional C-band interferometric applications. A stack of 53 ERS-1/2 C-band SAR scenes acquired between 1993 and 2000 in descending mode was processed with both the standard low-pass SBAS method and ISBAS. The latter revealed exceptional improvements in the coverage of ground motion solutions with respect to the standard approach. The number of identified coherent and intermittently coherent pixels increased by a factor of 26 with respect to the SBAS solution, and extended the coverage of results across unfavourable land covers, particularly for coniferous woodland, bog, acid grassland and heather. The greatest increase was achieved over coniferous woodland, which showed ISBAS/SBAS pixel density ratios above 300. Despite the intermittent nature of the ISBAS solutions, ISBAS provided velocity standard errors generally below $1-1.5 \mathrm{~mm} / \mathrm{yr}$, thus preserving good quality of the estimated ground motion rates.
\end{abstract}

Keywords: InSAR, SBAS, ISBAS, intermittent coherence, peatlands, land cover, image processing

\section{INTRODUCTION}

The sustainable use, conservation and preservation of peatlands and organic soils from further degradation are nowadays key environmental priorities at European level to mitigate effects of climate change, and this is particularly crucial in the UK, where shallow and deep peaty and organic-rich soils cover $\sim 30 \%$ of the total area of the country ${ }^{1}$.

Recent studies ${ }^{2,3}$ have revealed that monitoring long-term elevation changes in peatlands using C- and L-band Synthetic Aperture Radar Interferometry (InSAR) is feasible, and estimates of peat degradation and erosion, volume changes, carbon loss and $\mathrm{CO}_{2}$ emissions can be made building upon InSAR ground motion data and coherence maps. Monitoring areas of peat and other non-urban land cover types with InSAR is, nevertheless, challenging due to temporal decorrelation $^{4,5}$, especially when using shorter radar wavelengths, such as those within the C- and X-bands, which are mainly used by sensors onboard operating and recent SAR missions (e.g., ERS-1/2 and ENVISAT, RADARSAT-1/2, COSMO-SkyMed, TerraSAR-X). Presence of land with naturally-accumulated layers of dead plant material formed under waterlogged conditions generally does not favour the identification of either coherent targets with Small Baseline Subset (SBAS) approaches or Persistent Scatterers (PS) with PSI (PS Interferometry) methods. In addition to issues of temporal phase stability, local topography is also accountable for further geometric constrains ${ }^{6}$. Such limitations have been proven for Great Britain by the feasibility study of nationwide coverage recently undertaken at the British Geological Survey $(B G S)^{7,8}$, in which SAR geometric distortions and PS densities for ERS-1/2 and ENVISAT SARbased applications were modelled, revealing significant control of rural land cover of Great Britain on the success of single-pair and multi-temporal InSAR studies.

In this paper, an InSAR proof-of-concept to monitor peatlands is provided, and the limitations relating to land cover are dealt with by exploiting the newly developed Intermittent SBAS (ISBAS) technique ${ }^{9}$. The latter is a small baseline, multi-looked, coherent target method, which considers the intermittent coherence of rural areas and allows denser coverage of land deformation estimates and more complete picture of the spatial patterns of ground motion to be achieved $^{10}$.

* fcigna@bgs.ac.uk; phone +44 115936 3551; fax +44 1159363446 
The ISBAS processing solution is used here to provide optimum results from SAR imagery for rural areas in north Wales in the UK, the target of the Glastir Monitoring \& Evaluation Programme ${ }^{11}$, funded by the Welsh Government and led by the Centre for Ecology \& Hydrology. The investigated region is an area dominated by improved and acid grassland, heather, bog and coniferous woodland according to the UK Land Cover Map 2007 (LCM2007) ${ }^{12}$. These land covers are all very unlikely to produce dense networks of ground motion targets using standard PS, SBAS and interferogram stacking approaches ${ }^{7}$.

\section{INTERMITTENT SBAS ANALYSIS}

A stack of 53 ERS-1/2 C-band SAR images acquired between 1993 and 2000 is employed, these characterised by 35days repeat cycle (for each satellite), and 1day orbit phasing between ERS-1 and ERS-2 imagery during Tandem operations. The stack is processed using both the standard low-pass SBAS approach ${ }^{13}$ and the new ISBAS method ${ }^{9}$. The results are analysed in this work with focus on differences in the distribution, number and density of monitoring targets extracted by the two techniques, accounting for the degree of intermittence of the ISBAS solutions, and the observed ground motion rates and respective standard errors.

\subsection{ERS-1/2 SBAS and ISBAS processing}

The study focussed on a $\sim 63 \mathrm{~km}$ by $\sim 68 \mathrm{~km}$ subset of the ERS-1/2 scenes, for a total of 4,460 $\mathrm{km}^{2}$ processing area, centred at $-3.442^{\circ} \mathrm{E} 52.979^{\circ} \mathrm{N}$ (Figure 1), and including large regions of blanket bog peat $\left(\sim 335 \mathrm{~km}^{2}\right)$ and fen peat $(\sim 415$ $\mathrm{km}^{2}$ ) soils according to the 1:250,000 scale Soilscapes dataset for England and Wales produced by the National Soil Resources Institute, Cranfield University ${ }^{14}$.

The ERS-1/2 scenes were multi-looked by using factors of 4 and 20 along the range and azimuth directions respectively to reduce phase noise. With maximum perpendicular baseline of $200 \mathrm{~m}$ and temporal baseline threshold of 4 years, a redundant network of 300 interferograms was generated based on the image stack.

Only $4 \%$ of the scene revealed average coherence exceeding 0.25 , whilst the remainder showed lower values, especially over peat, grass, forest and heather. Pixels with average coherence over 0.25 were used to extract the standard SBAS solutions, whilst the intermittently coherent pixels were selected as those showing a minimum of 50 best interferograms with average coherence greater than 0.25 . By using such thresholds, the number of coherent interferograms needed for each intermittently coherent pixel to be included in the processing varies, clearly, between 50 (i.e. the selected threshold) and the total number of interferograms (i.e. 300), the latter achieved only by standard SBAS solutions. Analysis of the distribution of this indicator of intermittence across the subset shows that on average, the scene is characterized by pixels with around 120 best interferograms for which the average coherence is greater than 0.25 . The use of 50 as a threshold allows the vast majority of the image pixels to be considered in the analysis. Phase unwrapping and extraction of linear velocity solutions and associated errors, height corrections and time series were limited only to the two types of pixels selected using the thresholds mentioned above.

\subsection{SBAS vs. ISBAS solutions}

Figure 1 shows the coverage of standard SBAS solutions for the processed subset, classified based on the annual motion rates observed for the monitoring interval along the Line-Of-Sight (LOS) of ERS-1/2 SAR sensors. ISBAS dramatically improved the average pixel density by a factor of 26 with respect to conventional SBAS, with a total of over 25,000 SBAS targets, and over 640,000 ISBAS targets, for a total of over 665,000 (Figure 2).

Examples of coverage of the SBAS and ISBAS results and respective LCM2007 for inland rocks, suburban and urban land covers are shown in Figure 2(a-c) and (g-i). Comparison of SBAS and ISBAS target distribution does not reveal any major difference in the two results, as in both cases these regions are widely covered by ground motion targets. On average across the entire processing area, indeed, the ratio between ISBAS and SBAS solution is only 2 or 3.

The greatest increase was achieved over coniferous woodland, which showed ISBAS/SBAS pixel density ratios above 300. An example of SBAS with respect to ISBAS results for this land cover type is shown in Figure 2(h-i), where it is apparent that the conventional SBAS solution does not provide any target across this land cover, whilst several targets appear in the ISBAS solution. Bog, acid grassland and heather in Figure 2(d-f) showed densities increasing to 150-160 
pixels $/ \mathrm{km}^{2}$ when using ISBAS. Similarly, the same evidence is achieved for areas of grassland, for instance both rough grassland in Figure 2(g-i) and improved grassland in Figure 2(a-c).

Annual LOS rates of ground motion estimated from the SBAS results range between -5.4 and $+2.1 \mathrm{~mm} / \mathrm{yr}$ within the entire processing area, with lowest negative values observed in Abergele, at the northernmost margin of the subset, and $0.7 \mathrm{~mm} / \mathrm{yr}$ on average across the subset. Velocity standard errors are between 0.4 and $1.2 \mathrm{~mm} / \mathrm{yr}$, and $0.9 \mathrm{~mm} / \mathrm{yr}$ on average in the processed subset.

The range of annual velocities observed increases to -7.7 to $+8.0 \mathrm{~mm} / \mathrm{yr}$ in the ISBAS analysis. However, despite relying only on a temporal subset of interferograms, the vast majority of the ISBAS pixels shows velocity standard errors below $1.0-1.5 \mathrm{~mm} / \mathrm{yr}$, with a maximum of $2.5 \mathrm{~mm} / \mathrm{yr}$, hence a good quality of the estimated ground motion rates was generally preserved by using intermittently coherent targets.

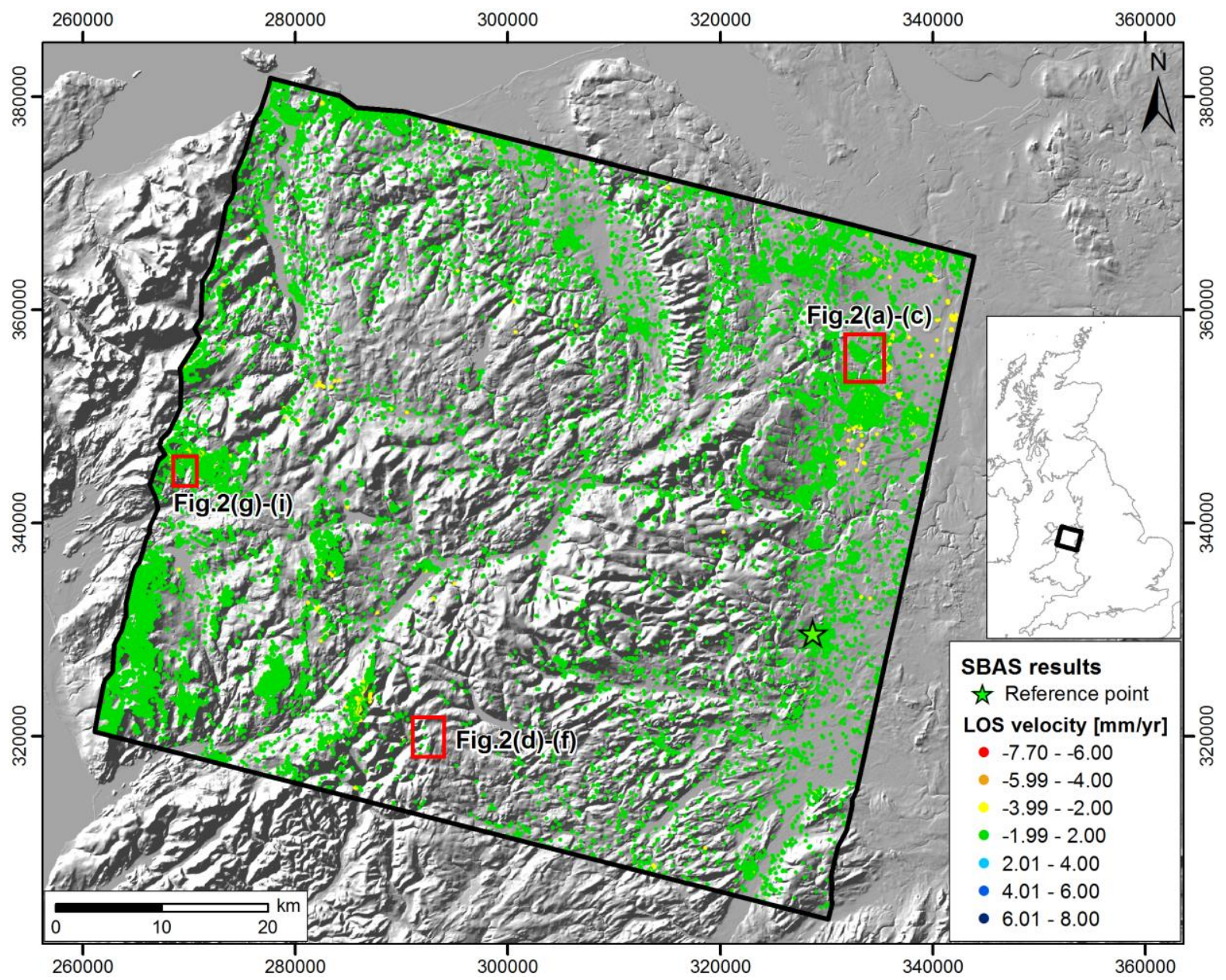

Figure 1: Low-pass SBAS ERS-1/2 solutions for north Wales, showing average motion rates observed between 1993 and 2000, overlapped onto 50m resolution NEXTMap DTM shaded relief. Datum: OSGB 1936. Vertical Datum: OSGM91. NEXTMap® Britain $\odot ~ 2003$, Intermap Technologies Inc., All rights reserved. 


\section{LCM2007}

Land cover class

$\square$ Unclassified

Broadleaved, mixed
and yew woodland

and yew woodland

Coniferous woodland

- Arable and horticulture

$\square$ Improved grassland

$\square$ Rough grassland

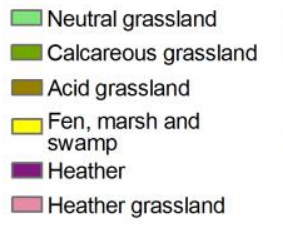

Bog

$\square$ Montane habitats

$\square$ Inland rock

- Saltwater

- Freshwater

$\square$ Supra-littoral rock
SBAS \& ISBAS

LOS velocity [mm/yr]

$\square$ Supra-littoral sediment

$-7.7-6.0$

$-5.9--4.0$

$-3.9--2.0$

$-1.9-2.0$

- $2.1-4.0$

- $4.1-6.0$

- $6.1-8.0$

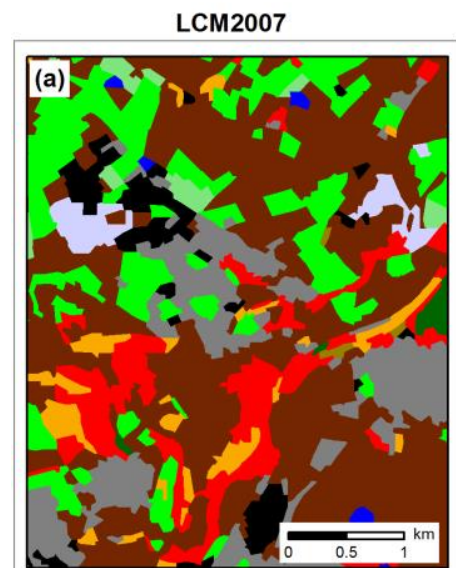

SBAS

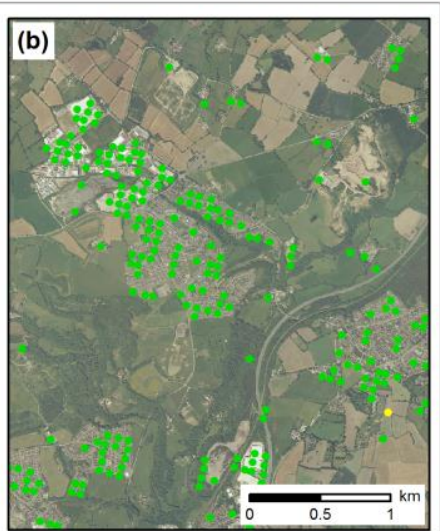

ISBAS
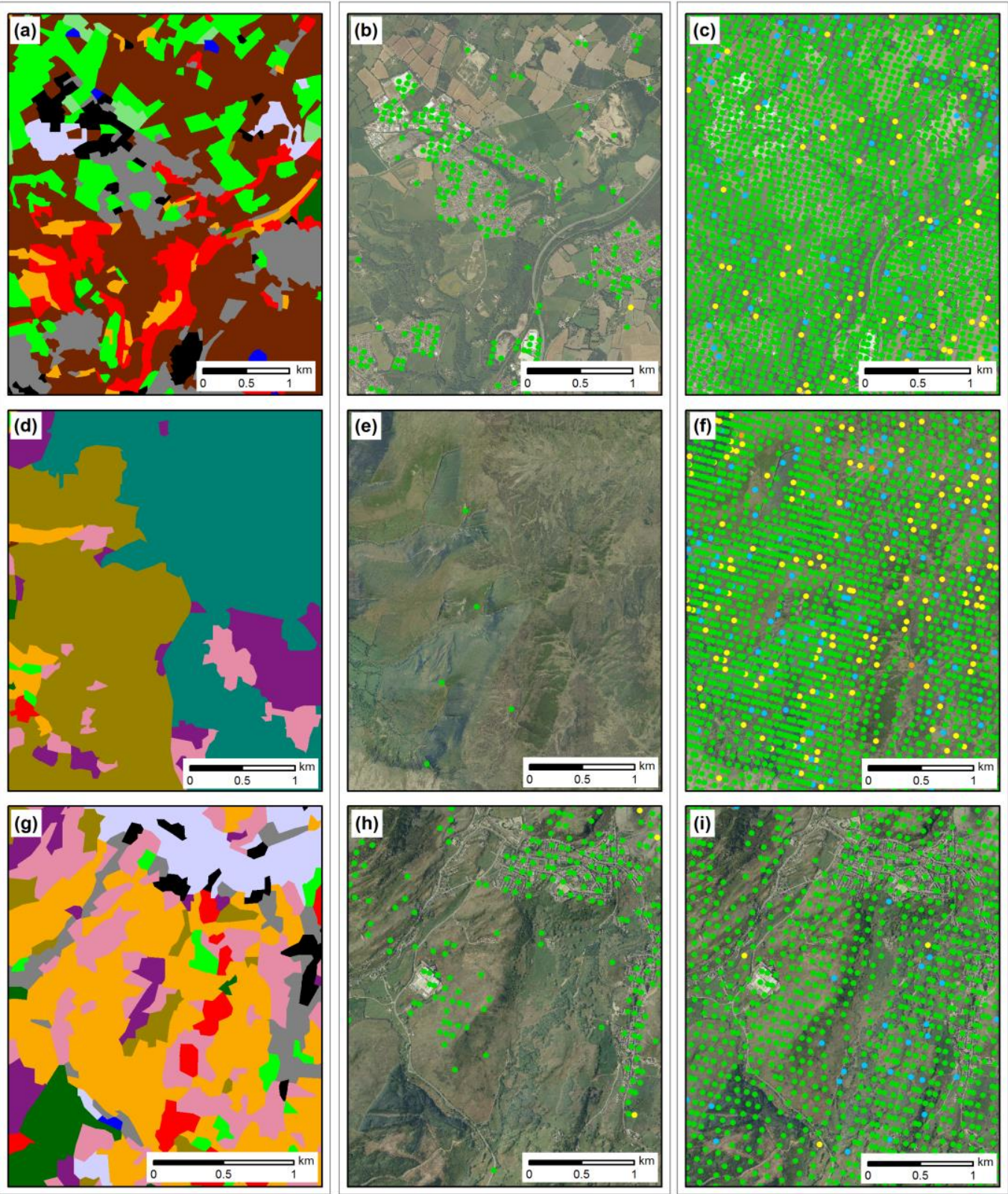

Figure 2: (a,d,g) LCM2007 class, (b,e,h) SBAS and (c,f,i) ISBAS solutions for three sectors of the processed scene Locations of these sectors are indicated in Figure 1. Datum: OSGB 1936. Vertical Datum: OSGM91. LCM2007 ( NERC (CEH) 2011. () Crown Copyright 2007, OS Licence no.100017572. () Third Party licensors. Aerial photography (C) UKP/Getmapping Licence No UKP2006/01. NEXTMap® Britain @ 2003, Intermap Technologies Inc., All rights reserved. 


\section{CONCLUSIONS}

This study provides a proof-of-concept for the use of InSAR methodologies and, in particular, the new Intermittent SBAS (ISBAS) approach to analyses of ground elevation changes in areas of peat and organic soils in north Wales which are, generally, unfavourable for conventional C-band interferometric applications.

The ISBAS technique was employed to process a stack of ERS-1/2 C-band SAR scenes and revealed exceptional improvements in the coverage of ground motion solutions with respect to a standard low-pass SBAS processing. The number of identified coherent and intermittently coherent pixels increased by a factor of 26 with respect to the SBAS solution, and extended the coverage of results across unfavourable land cover types within the processed subset, particularly for the LCM2007 classes of coniferous woodland, bog, acid grassland and heather. Although decreasing the number of interferograms used to extract the intermittent solution, ISBAS provided velocity standard errors generally below 1-1.5 mm/yr. Though no simultaneous GPS data from the British Isles continuous GNSS Facility (BIGF) sites are available for the processed subset, other geodetic monitoring data may be considered to perform external validation. Indepth analysis of observed degree of intermittence, cross-comparison of SBAS and ISBAS motion rates, and standard errors are in progress and will be discussed in relation to rainfall records and other monitoring data to accurately validate ISBAS observations for this area and relate them to peat elevation changes and degradation that occurred over the 7yearlong monitoring period.

\section{ACKNOWLEDGEMENTS}

This research is supported by BGS-NERC research funding under the EO Development project, ESA Category-1 project id.13543 with the provision of ERS-1/2 SAR imagery, and the Glastir Monitoring \& Evaluation Programme (GMEP), the latter funded by the Welsh Government. ERS-1/2 SAR scenes were processed by F. Cigna using the GAMMA software and MATLAB, both licensed to BGS-NERC, and Punnet and the ISBAS code developed at the University of Nottingham. Land Cover Map 2007 data was provided by CEH to BGS under the agreement LCM2011-178c_v3. The authors gratefully acknowledge the GMEP Project Leader Prof. B. Emmett, and the GMEP Consortium. F. Cigna, C. Jordan and B. Rawlins publish with the permission of the Executive Director of the BGS, NERC.

\section{REFERENCES}

[1] Joosten, H., Tapio-Biström, M. and Tol, S., [Peatlands - guidance for climate change mitigation through conservation, rehabilitation and sustainable use], Food and Agriculture Organization (FAO) of the United Nations and Wetlands International, Mitigation of Climate Change in Agriculture (MICCA) Programme, Second edition (2012).

[2] Zhou, Z., [The applications of InSAR time series analysis for monitoring long-term surface change in peatlands], PhD Thesis, University of Glasgow (2013).

[3] Caro-Cuenca, M. and Hanssen, R., "Subsidence due to peat decomposition in the Netherlands, kinematic observations from radar interferometry." FRINGE2007, Frascati (Italy), 6 pp. (2008).

[4] Zebker, H. A. and Villasenor, J., "Decorrelation in interferometric radar echoes," Geoscience and Remote Sensing, IEEE Transactions on, 30(5), 950-959 (1992).

[5] Plank, S., Singer, J. and Thuro, K., "Assessment of number and distribution of persistent scatterers prior to radar acquisition using open access land cover and topographical data," ISPRS Journal of Photogrammetry and Remote Sensing, 85, 132-147 (2013).

[6] Kropatsch, W. G. and Strobl, D., "The generation of SAR layover and shadow maps from digital elevation models," Geoscience and Remote Sensing, IEEE Transactions on, 28(1), 98-107 (1990).

[7] Cigna, F., Bateson, L. B., Jordan, C. J. and Dashwood, C., "Simulating SAR geometric distortions and predicting Persistent Scatterer densities for ERS-1/2 and ENVISAT C-band SAR and InSAR applications: Nationwide feasibility assessment to monitor the landmass of Great Britain with SAR imagery," Remote Sensing of Environment, 152, 441-466 (2014). 
[8] Cigna, F., Bateson, L., Jordan, C. and Dashwood, C., "Nationwide monitoring of geohazards in Great Britain with InSAR: feasibility mapping based on ERS-1/2 and ENVISAT imagery," IEEE International Geoscience and Remote Sensing Symposium (IGARSS), 672-675 (2013).

[9] Sowter, A., Bateson, L., Strange, P., Ambrose, K. and Syafiudin, M., "DInSAR estimation of land motion using intermittent coherence with application to the South Derbyshire and Leicestershire coalfield," Remote Sensing Letters, 4(10), 979-987 (2013).

[10] Bateson, L., Cigna, F., Boon, D. and Sowter, A., "The application of the Intermittent SBAS (ISBAS) InSAR method to the South Wales Coalfield, UK," International Journal of Applied Earth Observation and Geoinformation, (2014).

[11] Emmett, B., Abdalla, M., Anthony, S. et al., [Glastir Monitoring \& Evaluation Programme. First year annual report], NERC/Centre for Ecology \& Hydrology, 242pp. (2014).

[12] Morton, D., Rowland, C., Wood, C., Meek, L., Marston, C., Smith, G., Wadsworth, R. and Simpson, I. C., [Final Report for LCM2007 - the new UK Land Cover Map], Countryside Survey Technical Report No.11/07 NERC/Centre for Ecology \& Hydrology, 112 pp. (2011).

[13] Berardino, P., Fornaro, G., Lanari, R. and Sansosti, E., "A new algorithm for surface deformation monitoring based on small baseline differential SAR interferograms," Geoscience and Remote Sensing, IEEE Transactions on, 40(11), 2375-2383 (2002).

[14] Farewell, T. S., Truckell, I. G., Keay, C. A. and Hallett, S. H., [Use and applications of the Soilscapes datasets], National Soil Resources Institute - Cranfield University, First Edition, 23 pp. (2011). 